\title{
Take-Up of Public Insurance and Crowd-Out of Private Insurance under Recent CHIP Expansions to Higher Income Children
}

\author{
Carole Roan Gresenz, Sarah E. Edgington, Miriam Laugesen, and \\ JoséJ. Escarce
}

Objective. To analyze the effects of states' expansions of Children's Health Insurance Program (CHIP) eligibility to children in higher income families on health insurance coverage outcomes.

Data Sources. 2002-2009 Current Population Survey linked to multiple secondary data sources.

Study Design. Instrumental variables estimation of linear probability models. Outcomes are whether the child had any public insurance, any private insurance, or no insurance coverage during the year.

Principal Findings. Among children in families with incomes between two and four times the federal poverty line (FPL), four enrolled in CHIP for every 100 who became eligible. Roughly half of the newly eligible children who took up public insurance were previously uninsured. The upper bound "crowd-out" rate was estimated to be 46 percent.

Conclusions. The CHIP expansions to children in higher income families were associated with limited uptake of public coverage. Our results additionally suggest that there was crowd-out of private insurance coverage.

Key Words. CHIP, insurance, crowd-out

A rich literature has explored the effects of public health insurance expansions, including the Medicaid expansions of the late 1980s and the introduction of the Children's Health Insurance Program (CHIP) in 1996, on take-up of public coverage, crowd-out of private coverage, and insurance coverage rates (Cutler and Gruber 1996; Lo Sasso and Buchmueller 2004; Ham and Shore-Sheppard 2005; Hudson, Selden, and Banthin 2005; Bansak and Raphael 2006; Sommers et al. 2007; Shore-Sheppard 2008). However, existing studies of CHIP extend through 2002, and none has explored the effects 
on coverage outcomes of the changes in eligibility associated with CHIP expansions over the last decade. The novel feature of these expansions is the extension of eligibility for subsidized coverage to higher income children in a range of states.

In this research brief, we analyze the effects of CHIP expansions from 2002 to 2009 on take-up of public coverage, crowd-out of private coverage, and rates of insurance coverage among children in families with incomes between 200 and 400 percent of the federal poverty line (FPL). We targeted this income group because studies of earlier CHIP expansions have focused on lower income children. Our results provide new empirical evidence about how the availability of subsidized public insurance to higher income families affects coverage outcomes. In addition, we describe the implications of our results for the Affordable Care Act (ACA).

\section{CHANGES TO CHIP-2002-2009}

Between 2002 and 2009, 18 states increased their income eligibility threshold for CHIP (Figure 1). (Table A1 lists maximum income eligibility thresholds by state for 2002 and 2009.) In a few states, the changes were modest, but in 13 states, the income threshold was boosted to between 200 and 400 percent FPL, with seven states extending eligibility to those with incomes between three times $(\$ 66,150$ in 2009) and four times $(\$ 88,200$ in 2009) the FPL (Kaiser Commission on Medicaid and the Uninsured 2002, 2003, 2004, 2005, 2006, 2007, 2008, 2009a,b). Many states also imposed requirements that families share in the cost of public coverage with premium contributions. By 2008, most states required at least some premium contribution for a subset of CHIP enrollees; only 16 states had no such requirements at any income level. Among the states that offered coverage to families with incomes at least three times FPL, premium contribution requirements ranged from $\$ 240$ to more than $\$ 1,000$ per year for a family with two children. States additionally

Address correspondence to Carole Roan Gresenz, Ph.D., Senior Economist, RAND Corporation, 1200 S. Hayes Street, Arlington, VA 22202; e-mail: gresenz@rand.org. Sarah E. Edgington, M.A., is with the Division of General Internal Medicine and Health Services Research, Department of Medicine, David Geffen School of Medicine at UCLA, Los Angeles, CA. Miriam Laugesen, Ph.D., is an Assistant Professor in the Department of Health Policy and Management, Mailman School of Public Health, Columbia University, New York, NY. José J. Escarce, M.D., Ph.D., is a Professor of Medicine in the David Geffen School of Medicine at UCLA, Los Angeles, $\mathrm{CA}$, and is a Senior Natural Scientist with the RAND Corporation, Santa Monica, CA. 
Figure 1: Changes in CHIP Maximum Income Eligibility Thresholds among Expansion States: 2002-2009

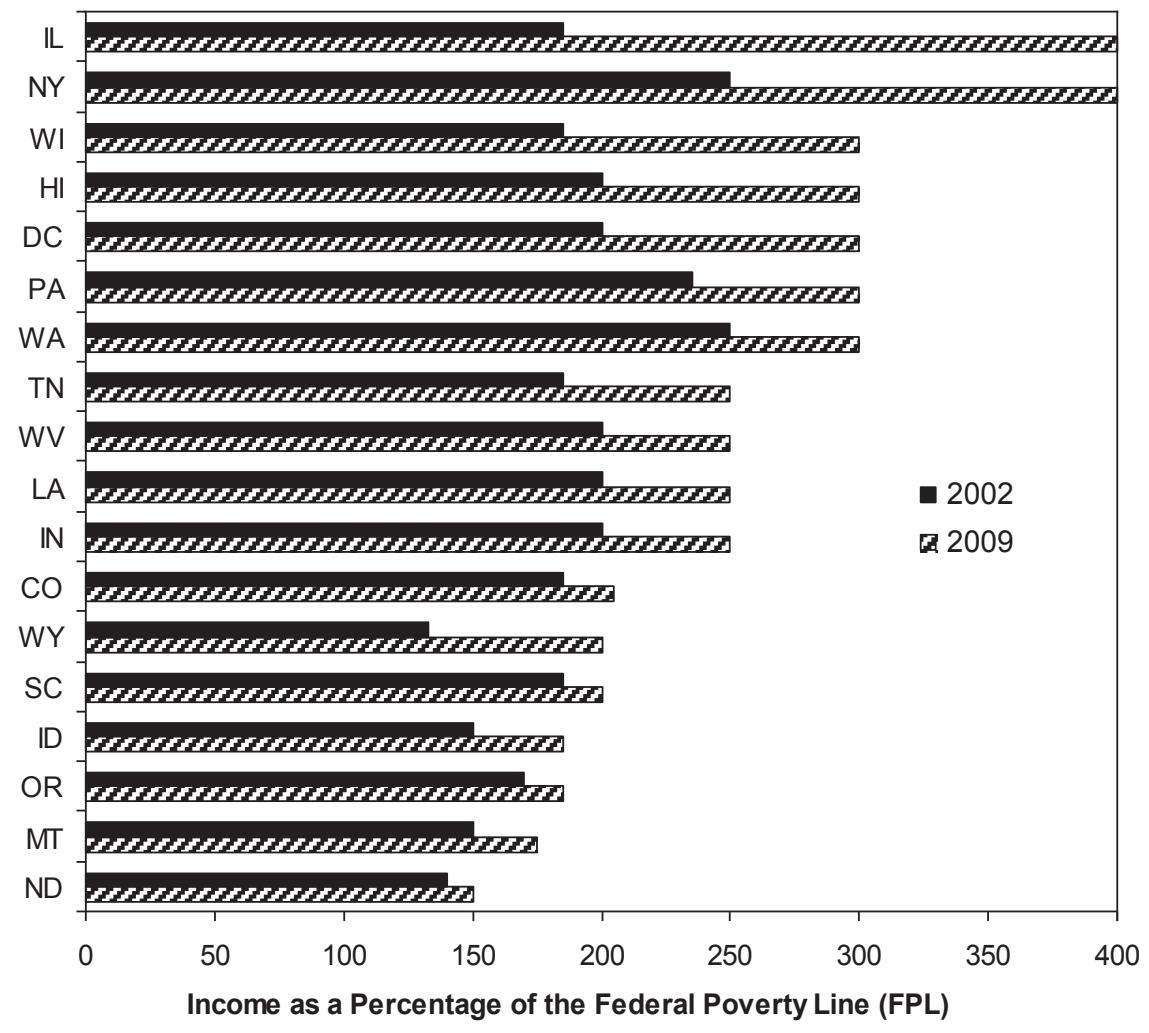

implemented a variety of program modifications intended to enhance takeup, such as targeted outreach efforts, marketing of the program to reduce stigma associated with participation in a public program, and streamlined administrative processes for enrollment or renewal, as well as measures designed to reduce crowd-out of private coverage, such as waiting periods between loss of private coverage and public eligibility (State Health Access Data Assistance Center [SHADAC] 2009).

\section{PREVIOUS EVIDENCE ON TAKE-UP AND CROWD-OUT}

Take-up and crowd-out have been studied in the context of Medicaid expansions of the 1980s (Cutler and Gruber 1996; Ham and Shore-Sheppard 2005; 
Shore-Sheppard 2008) and in the context of CHIP implementation (Lo Sasso and Buchmueller 2004; Hudson, Selden, and Banthin 2005; Bansak and Raphael 2006; Sommers et al. 2007; Gruber and Simon 2008; Dubay and Kenney 2009). For children made eligible through Medicaid expansions, Cutler and Gruber (1996) reported a 24 percent take-up rate and Shore-Sheppard (2008) a 15-19 percent take-up rate. By comparison, Lo Sasso and Buchmueller (2004) estimated a take-up rate of between 5.4 and 9.1 percent and Gruber and Simon (2008) reported a 7.2 percent take-up rate among children made eligible for public insurance through CHIP.

Crowd-out estimates have varied according to the specific eligibility change studied, the timing of the measurement of health insurance, the definition of crowd-out, the specification of controls in the analysis, and the type of data used (administrative program data versus data from population-based surveys). Furthermore, the statistical uncertainty around crowd-out estimates has been infrequently analyzed and reported (Davidson, Blewett, and Call 2004). Among studies of CHIP, Lo Sasso and Buchmueller (2004) reported an average crowd-out rate across states of about 50 percent; Hudson, Selden, and Banthin (2005) reported a range from 35 to 70 percent; and the central estimate from Gruber and Simon's analyses (2008) was 60 percent.

\section{DATA AND METHODS}

\section{Data Sources}

Our main sources of data were the 2002-2009 Annual Social and Economic Supplements (ASEC) of the Current Population Survey (CPS). The CPSASEC, which is administered each February-April by the U.S. Census Bureau, collects labor market, sociodemographic, and health insurance data from samples of households that are representative of each state. The health insurance questions enable researchers to classify children's coverage as public (Medicaid or CHIP), private (group or non-group), or none, and subjects are allowed to report both public and private coverage. The study sample consisted of children younger than 18 who were in families with incomes between 200 and 400 percent of the FPL. ${ }^{1}$

We compiled data from various sources to characterize eligibility criteria for states' CHIP programs, including income eligibility thresholds and income disregards, and to describe whether CHIP is integrated with the state's Medicaid program or separate, and whether the state has a waiver that allows for parental eligibility (Bissell and Allen 2001; Kaiser Commission on 
Medicaid and the Uninsured 2002, 2003, 2004, 2005, 2006, 2007, 2008, 2009a, 2009b; TRIM3 2011). We obtained state-level estimates of unemployment rates, poverty rates among children, unionization rates, and per capita income from CPS data. We obtained information on the employee share of private insurance premiums for family coverage by firm size for each state and year from summary tables from the Medical Expenditure Panel Survey-Insurance Component (MEPS-IC), and used these data to calculate a state-level measure of the average price of private insurance by weighting the average premium for each firm size category within a state by the percentage of workers in each firm size category.

\section{Econometric Analysis}

Our analyses were based on multivariate linear probability models. We analyzed each of three coverage outcomes: whether the child had any public insurance during the year, whether the child had any private insurance during the year, and whether the child had no insurance coverage during the year. The key independent variable of interest was CHIP eligibility. We used the information we obtained on states' eligibility criteria in each year to impute eligibility for individual children using the demographic and socioeconomic data reported in the CPS-ASEC.

As previous studies have highlighted, two concerns about the eligibility variable are that it is measured with error, given limitations of the survey data, ${ }^{2}$ and that it is potentially endogenous, given families' ability to modify their income to meet an eligibility threshold through job choice or hours worked. To address these concerns, we used instrumental variables estimation, which yields unbiased estimates when there is measurement error or endogeneity in an independent variable. Our instrument for eligibility was first described by Cutler and Gruber (1996) and has been used in subsequent studies (Lo Sasso and Buchmueller 2004; Hudson, Selden, and Banthin 2005; Bansak and Raphael 2006). The instrument was the percentage of a random sample of children of a particular age in families with incomes between 200 and 400 percent of the FPL from all states in a particular year who would have been eligible for public insurance in that state and year under the rules in place in that state at that time. We derived the instrument (a different value for each age-state-year cell) using a sample of 300 children from each age group and year.

The covariates in the models include a comprehensive set of individual and family characteristics including the age, race, and gender of the child; the size of the family and household structure; parental assessment of child's 
health; highest level of education for either parent; parental employment indicators; a set of indicators for whether the child is foreign born or his/her parent is foreign born and length of time the child has been in the United States; and family income as a percentage of the poverty line. We also include selected characteristics of each state to control for their potential direct effect on insurance coverage outcomes and relationship with policy changes affecting eligibility: current and lagged unemployment, per capita income, the percentage of children age $0-5$ in the state who live in poverty, the percentage of children age $6-18$ in the state living in poverty, the percentage of employed individuals in the state who are unionized, and the price of private insurance. We additionally include controls for whether the CHIP program is integrated with Medicaid or separate, and whether the state allows parents of children eligible for CHIP to themselves be eligible for CHIP. ${ }^{3}$ Finally, covariates include year and state fixed effects. We also perform sensitivity analyses that allow for different trends in each state for particular age groups of children and different trends over time for specific age groups by including state-age and year-age interactions (Shore-Sheppard 2008).

Estimates were weighted and standard errors were adjusted for weighting and clustering to reflect the complex design of the CPS, as recommended by Davern et al. (2007).

\section{RESULTS}

The analytic sample includes 157,315 children in families with incomes between 200 and 400 percent of the FPL. Table 1 provides descriptive statistics for the sample of children from 2009.

Table 2 presents regression results for the three study outcomes: take-up of public coverage, reduction in private coverage, and increase in insurance coverage rates. (Tables A2-A3 provide full regression results.) Specifically, we report the number of children who enroll in public coverage, drop private coverage, and move out of uninsurance per 100 children who become newly eligible for subsidized public insurance.

We found that, for every 100 children who became eligible for public insurance, approximately 4 took up public coverage and $\sim 2$ children fell from the ranks of the uninsured (Table 2, Specification 1). The effect on the number of children who have private coverage was not statistically significant. Our findings were robust to the inclusion of state-age and year-age interactions as controls, as shown in Specification 2. 


\section{Table 1: Descriptive Statistics}

Mean (SD)

Dependent variables

Public insurance*

$0.133(0.340)$

Private insurance*

$0.844(0.362)$

No insurance*

$0.072(0.259)$

Independent variables

Individual and family characteristics

Eligible for public insurance (imputed)

$0.394(0.489)$

Non-Hispanic white

$0.641(0.480)$

Non-Hispanic black

$0.129(0.335)$

Hispanic

$0.173(0.378)$

Other race

$0.057(0.232)$

Age 0-2

$0.156(0.363)$

Age 3-5

$0.162(0.369)$

Age 6-12

$0.386(0.487)$

Age 13-18

$0.296(0.456)$

Male

$0.512(0.500)$

Family with one child

$0.206(0.404)$

Family with two children

$0.424(0.494)$

Family with three children

$0.245(0.430)$

Family with four children

$0.088(0.284)$

Family with five or more children

$0.036(0.187)$

Reported health is good, fair, or poor

$0.155(0.362)$

Parent with highest level of education is college graduate

$0.380(0.485)$

Parent with highest level of education attended some college

$0.363(0.481)$

Parent with highest level of education is high school graduate or has GED

$0.221(0.415)$

Neither parent is high school graduate

$0.036(0.186)$

Foreign born, lived in U.S. $\leq 5$ years

$0.010(0.101)$

Foreign born, lived in U.S. $>5$ years

$0.014(0.118)$

U.S. born with no U.S. born parent/grandparent

$0.112(0.315)$

U.S. born with at least one U.S. born parent/grandparent

$0.864(0.343)$

Urban location

Two-parent family

Family income 201-250\% FPL

Family income $251-300 \%$ FPL

$0.824(0.381)$

$0.785(0.411)$

$0.303(0.460)$

$0.273(0.446)$

Family income $301-350 \%$ FPL

$0.227(0.419)$

Family income $351-400 \%$ FPL

$0.196(0.397)$

Either parent is FT public sector employee ${ }^{\dagger}$

$0.216(0.412)$

Either parent is a FT private sector employee ${ }^{\dagger}$

$0.688(0.463)$

Either parent is FT self-employed ${ }^{\dagger}$

$0.043(0.204)$

Either parent works part-time

$0.042(0.200)$

Neither parent is employed ${ }^{\dagger}$

$0.010(0.100)$

Firm size $<10$ for parent employed in private sector ${ }^{*}$

$0.059(0.236)$

Firm size 10-24 for parent employed in private sector

$0.051(0.220)$

Firm size 25-99 for parent employed in private sector

$0.101(0.302)$ 
Table 1. Continued

\begin{tabular}{|c|c|}
\hline & Mean $(S D)$ \\
\hline Firm size $100-499$ for parent employed in private sector & $0.114(0.318)$ \\
\hline Firm size $500-999$ for parent employed in private sector & $0.049(0.216)$ \\
\hline Firm size $1000+$ for parent employed in private sector & $0.314(0.464)$ \\
\hline Occupation $=$ management, professional for parent employed in private sector ${ }^{*}$ & $0.294(0.456)$ \\
\hline Occupation $=$ production, transport for parent employed in private sector & $0.130(0.336)$ \\
\hline Occupation $=$ sales $\&$ office for parent employed in private sector & $0.144(0.351)$ \\
\hline Occupation = construction \& maintenance for parent employed in private sector & $0.069(0.254)$ \\
\hline Occupation $=$ service for parent employed in private sector & $0.033(0.180)$ \\
\hline Occupation $=$ farming, fishing, forestry for parent employed in private sector & $0.001(0.035)$ \\
\hline Occupation $=$ unknown for parent employed in private sector & $0.015(0.123)$ \\
\hline \multicolumn{2}{|l|}{ State-level characteristics } \\
\hline Percent unemployed & $0.093(0.019)$ \\
\hline Lagged percent unemployed & $0.054(0.011)$ \\
\hline Per capita income (in $\$ 100,000)$ & $0.268(0.030)$ \\
\hline Percent of children $0-5$ in poverty & $0.219(0.048)$ \\
\hline Percent children $6-18$ in poverty & $0.179(0.036)$ \\
\hline Rate of unionization & $0.122(0.064)$ \\
\hline Private insurance premium (in $\$ 10,000$ ) & $0.402(0.046)$ \\
\hline \multicolumn{2}{|l|}{ Program characteristics } \\
\hline Parental CHIP eligibility waiver & $0.177(0.382)$ \\
\hline Separate CHIP program & $0.856(0.351)$ \\
\hline
\end{tabular}

Notes. Descriptive statistics are for 18,514 children in the CPS with incomes between 200 and 400 percent of the FPL in the 2009 CPS. Full analytic data include 157,315 children. FT indicates full-time.

*Sum across insurance categories (public, private, no insurance) exceeds 1 because individuals can report public and private insurance.

†Parental employment categories are mutually exclusive and follow hierarchy in listed order.

*Variable means for firm size categories total percentage of families with a FT private sector employee; same for occupational categories.

Table 2: Effects of Expanded CHIP Eligibility on Take-Up of Public Coverage, Reductions in Private Coverage, and Insurance Coverage, 2002-2009

\begin{tabular}{lcc} 
Per 100 Children Who Become Eligible: & Specification (1) & Specification (2) \\
\hline Number who enroll in public coverage & $4.21^{* * *}$ & $4.12^{* * *}$ \\
Number who drop private coverage & -0.14 & -0.19 \\
Number who move from being uninsured to being insured & $2.26^{* * *}$ & $2.31^{* * *}$ \\
\hline
\end{tabular}

Notes. Specification 1 includes the full set of individual and family characteristics, state characteristics, program characteristics, and state and year fixed effects, as described in the text. Specification 2 additionally includes state-age and year-age controls. ${ }^{* * * *} p<.01$.

A noteworthy finding in Table 2 is that the number of children who took up public coverage exceeds the sum of the number of children who drop private coverage and the number of uninsured children who gain insurance 
coverage. This finding reflects the fact that after a public insurance expansion the number of persons who report both private and public insurance in population-based datasets like the CPS rises (Gruber and Simon 2008). The degree to which this rise is due to more children having both types of coverage simultaneously or due to transitions between types of coverage is unknown.

The phenomenon described in the preceding paragraph has led researchers to develop two alternative methods for measuring crowd-out (Cutler and Gruber 1996; Davidson, Blewett, and Call 2004). Under a "narrow" definition, crowd-out is measured as the number of children who drop private coverage divided by the number of children who enroll in public coverage. Under a "broad" definition, crowd-out is measured by calculating how much of the increase in public insurance is not explained by a decrease in uninsurance. ${ }^{4}$ Using the narrow definition, the point estimate for crowd-out is not statistically different from zero (Table 3). By contrast, using the broad definition, the point estimate for crowd-out is roughly 46 percent and is statistically significant $(p<.05)$. Thus, at most 46 percent of the increase in public coverage could potentially have come from children who switched from private coverage.

\section{DISCUSSION}

The 2002-2009 expansions to CHIP eligibility were associated with very limited take-up of public insurance among children in families with incomes between two and four times the FPL, with four children enrolling for every 100 who became newly eligible. That such a small proportion of children newly eligible for public insurance actually enrolled may seem surprising, but our estimate is only slightly lower than earlier estimates of the effect of CHIP eligibility on take-up (Lo Sasso and Buchmueller 2004; Hudson, Selden, and Banthin 2005; Gruber and Simon 2008). The fact that our estimate is lower is likely explained by the fact we studied a higher income population than that in previous studies.

Table 3: Estimates of Crowd-Out Associated with CHIP Expansions, 2002-2009

\begin{tabular}{lc} 
Per 100 Children Who Take up Public Coverage & Specification (1) \\
\hline Crowd-out estimate, narrow definition & 3.3 \\
Crowd-out estimate, broad definition & $46.3^{* *}$
\end{tabular}

Note. Standard errors derived using the delta method. ${ }^{* * *} p<.05$. 
Our findings further suggest that, for every 100 children in families with incomes between 200 and 400 percent of the FPL who became eligible for public insurance, only two moved from being uninsured to having insurance coverage. The observation that only half of the children who took up public coverage were accounted for by uninsured children who gained coverage may be explained by crowd-out of private insurance coverage, more children holding both public and private coverage simultaneously or, most likely, a combination of the two.

Our study has several limitations, most of which arise from the limitations of the CPS-ASEC data. First, there is controversy about the time period to which insurance coverage information obtained from the CPS-ASEC actually applies. Although the interview questions are intended to elicit information from subjects about coverage during the preceding year, indirect evidence suggests that this is not the case (Swartz 1986). In this study, we considered the coverage data to apply to the year of the interview. However, our results and conclusions did not change when we considered the coverage data to refer to the year preceding the interview. Second, some investigators have argued that distinctions between public coverage and non-group (i.e., individual) private coverage in the CPS-ASEC data may not be reliable (Lo Sasso and Buchmueller 2004). However, modifications in the interview instrument implemented in the early part of this decade were specifically aimed at improving this distinction. In preliminary analyses (data not shown), we found that reported non-group coverage behaved much more like group coverage than like public coverage.

Just as premiums for CHIP coverage are subsidized under the expansions we studied, so too will premium costs be subsidized under the ACA for insurance coverage that families with incomes under 400 percent of the FPL purchase through health insurance exchanges. Although it is impossible to know what the attractiveness of subsidized exchange-based coverage will be to middle-income families, our results suggest that the availability of subsidized health insurance coverage for families with incomes up to 400 percent FPL alone, in the absence of a mandate, will not solve the problem of the uninsured.

\section{ACKNOWLEDGMENT}

Joint Acknowledgment/Disclosure Statement: This research was supported by a grant (64211) from the Robert Wood Johnson Foundation's State Health Access Reform Effort (SHARE). We thank Idalid Franco for her excellent research assistance. 
Disclosures: None.

Disclamiers: None.

\section{NOTES}

1. Children above 400 percent FPL may be eligible to enroll in public insurance at full cost (i.e., with zero subsidy) in some states; however, the availability of these types of unsubsidized options for families is not comprehensively documented in the available data.

2. We do not observe all the factors that may influence eligibility. For example, the CPS does not include information on assets, length of time an individual has been uninsured, or eligibility for employer-sponsored insurance. However, by available metrics, our imputation process is comparable if not better than those used in previous studies. In particular, about 8 percent of children who reported public insurance in the CPS-ASEC were imputed to be ineligible for public coverage, which compares favorably with approximately 20 percent for Cutler and Gruber (1996) and Lo Sasso and Buchmueller (2004) and 11 percent for Bansak and Raphael (2006).

3. We do not control for features of states' CHIP programs such as premium contribution required, waiting period for eligibility, active/passive renewal, or marketing/ outreach, for example. Rather, in keeping with several published studies (e.g., Hudson, Selden, and Banthin 2005; Dubay and Kenney 2009), our analyses estimate the net effects of the expansions, given all the various ways in which states implemented them.

4. The narrow definition treats private coverage for the additional children who report both types of coverage as not being crowded-out and assumes these children actually hold both types of coverage simultaneously; it provides a lower bound on crowd-out. The broad definition treats private coverage for the additional children who report both types of coverage as being crowded-out and assumes these children were transitioning from private to public coverage; it provides an upper bound on crowd-out.

\section{REFERENCES}

TRIM3 project website. [accessed on October 26, 2011]. Available at http://trim3. urban.org

Bansak, C., and S. Raphael. 2006. "The Effects of State Policy Design Features on Take-up and Crowd-out Rates for the State Children's Health Insurance Program.”Journal of Policy Analysis and Management 26 (1): 149-75.

Bissell, M.K., and M. Allen. 2001. Healthy Ties: Ensuring Health Coverage for Children Raised by Grandparents and Other Relatives. Washington, DC: Children's Defense Fund [accessed November 15, 2010]. Available at http://cdf.childrensdefense. org/site/DocServer/healthyties_fullreport.pdf?docID $=638$. 
Cutler, D.M., and J. Gruber. 1996. "Does Public Insurance Crowd Out Private Insurance?" Quarterly Journal of Economics 111 (2): 391-430.

Davern, M., A. Jonese, J. Lepkowski, G. Davidson, and L.A. Blewett. May 2007. "Estimating Regression Standard Errors with Data from the Current Population Survey's Public Use File." Inquiry 44 (2): 211-24.

Davidson, G., L.A. Blewett, and K.T. Call. June 2004. Public Program Crowd Out of Private Coverage: What Are the Issues? Princeton, NJ: Robert Wood Johnson Foundation. Research Synthesis Report No. 5 [accessed on October 26, 2011]. Available at http://www.shadac.org/files/CrowdOut_Report_Jun04.pdf

Dubay, L., and G. Kenney. 2009. "The Impact of CHIP on Children's Insurance Coverage: An Analysis Using the National Survey of America's Families,." Health Services Research 44 (6): 2040-59.

Gruber, J., and K. Simon. 2008. "Crowd-Out Ten Years Later: Have Recent Public Insurance Expansions Crowded Out Private Health Insurance?” Journal of Health Economics 27: 201-17.

Ham, J.C., and L. Shore-Sheppard. 2005. "The Effect of Medicaid Expansions for Low-Income Children on Medicaid Participation and Private Insurance Coverage: Evidence from the SIPP.” Journal of Public Econonomics 89: 57-83.

Hudson, J., T. Selden, and J. Banthin. 2005. "The Impact of SCHIP on Insurance Coverage of Children." Inquiry 42 (3): 232-54.

Kaiser Commission on Medicaid and the Uninsured. June 12, 2002. Enrolling Children and Families in Health Coverage: The Promise of Doing More. Washington, DC: Kaiser Family Foundation.Publication 4046.

Kaiser Commission on Medicaid and the Uninsured. July 29, 2003. Preserving Recent Progress for Health Coverage of Children and Parents: New Tensions Emerge. Washington, DC: Kaiser Family Foundation. Publication 4125.

Kaiser Commission on Medicaid and the Uninsured. October 4, 2004. Beneath the Surface: Barriers Threaten to Slow Progress on Expanding Health Coverage of Children and Families. Washington, DC: Kaiser Family Foundation.Publication 7191.

Kaiser Commission on Medicaid and the Uninsured. October 18, 2005. In a Time of Growing Need: State Choices Influence Health Coverage Access for Children and Families. Washington, DC: Kaiser Family Foundation. Publication 7393.

Kaiser Commission on Medicaid and the Uninsured. October 13, 2006. Making It Simple: Medicaid for Children and CHIP Income Eligibility Guidelines and Enrollment Procedures. Washington, DC: Kaiser Family Foundation. Publication 2166.

Kaiser Commission on Medicaid and the Uninsured. January 9, 2007. Resuming the Path to Health Coverage for Children and Parents: A 50-State Update on Eligibility Rules, Enrollment and Renewal Procedures, and Cost-Sharing Practices in Medicaid and SCHIP in 2006. Washington, DC: Kaiser Family Foundation. Publication 7608.

Kaiser Commission on Medicaid and the Uninsured. January 28, 2008. Health Coverage for Children and Families in Medicaid and SCHIP: State Efforts Face New Hurdles. Washington, DC: Kaiser Family Foundation. Publication 7740.

Kaiser Commission on Medicaid and the Uninsured. December 8, 2009a. A Foundation for Health Reform: Findings of a 50 State Survey of Eligibility, Enrollment and Renewal 
Procedures, and Cost-Sharing Practices in Medicaid and CHIP for Children and Parents During 2009. Washington, DC: Kaiser Family Foundation. Publication 8028.

Kaiser Commission on Medicaid and the Uninsured. January 23, 2009b. Challenges of Providing Health Coverage for Children and Parents in a Recession: A 50 State Update on Eligibility Rules, Enrollment and Renewal Procedures, and Cost-Sharing Practices in Medicaid and SCHIP in 2009. Washington, DC: Kaiser Family Foundation. Publication 7855.

Lo Sasso, A.T., and T.C. Buchmueller. 2004. "The Effect of the State Children's Health Insurance Program on Health Insurance Coverage." Journal of Health Economics 23: 1059-82.

Shore-Sheppard, L. 2008. "Stemming the Tide? The Effect of Expanding Medicaid Eligibility on Health Insurance." The B.E. Journal of Economic Analysis and Policy 8 (2): 1-33. Article 6 [accessed on October 26, 2011]. Available at http://works. bepress.com/lara_shore_sheppard/1

Sommers, A., S. Zuckerman, L. Dubay, and G. Kenney. 2007. "Substitution of SCHIP for Private Coverage: Results from a 2002 Evaluation in Ten States." Health Affairs 26 (2): 529-37.

State Health Access Data Assistance Center (SHADAC). August 2009, Comprehensive Coverage for Children [Policy Summary]. Los Angeles, CA: Robert Wood Johnson Foundation and SHADAC.

Swartz, K. 1986. "Interpreting the Estimates from Four National Surveys on the Number of People without Health Insurance." Journal of Economic and Social Measurement 14 (3): 233-42.

\section{SUPPORTING INFORMATION}

Additional supporting information may be found in the online version of this article:

Appendix SA1: Author Matrix.

Table A1: Changes in CHIP Maximum Income Eligibility Thresholds by State: 2002-2009.

Table A2: Full Regression Results for Table 2, Specification (1).

Table A3: Full Regression Results for Table 2, Specification (2).

Please note: Wiley-Blackwell is not responsible for the content or functionality of any supporting materials supplied by the authors. Any queries (other than missing material) should be directed to the corresponding author for the article. 